\title{
Reflections and Explorations on the Employment of College Graduates Shui Yao
}

\author{
Physics and Space Science College, China West Normal University, nanchong Sichuan China \\ heyanqi11@sina.cn
}

Key words: university students, Employment, instructor.

\begin{abstract}
The employment of university students is the core issue in the employment problem in China. Looking at the current employment phenomenon of undergraduates with the view of development, we can find that there are many thought-provoking questions behind this phenomenon. This article analyzes the status quo of the employment of college students, especially for the employment psychology of college students, from the counselor's point of view, combined with the causes to propose solutions.
\end{abstract}

\section{Introduction}

Since 1999, colleges and universities began to expand the scale of enrollment, the number of graduates has been increasing, the phenomenon of employment difficulties for college students has become more prominent, the employment of college students is facing more and more serious challenges and pressure. In the face of this increasingly fierce employment competition, the difficulties and setbacks encountered by college students in the process of selecting jobs are also becoming more and more serious. Therefore, graduates are often exposed to various fears and uneasiness. If these emotions are not properly channeled, they will The physical and mental health of college students is harmful, even causing serious psychological problems. Therefore, under the severe background, as college counselors, it is of great significance to study the employment of college students.

\section{Reasons for difficult employment for college students}

The current "difficulty in employment" does not mean that it is difficult for a university student to find a job after graduation, but that it is more difficult to find a job that is "stable, high-paying, and decent". There are several main reasons for summing up:

\subsection{Personal reasons}

It is far too high to understand the reality correctly. Most students are changing their fate and turning to life to study. They hope that after graduation, they will find decent,high-status jobs, they will not engage in low-paying jobs, and they will be less willing to start from the grassroots, so when they are looking for a job, The choice of picking, picking, picking, picking, picking, picking up, graduating from unemployment. When some students choose to work, they regard the region as the primary condition for finding a job, resulting in overcrowding in places where the economy is better, college students "surplus", and lack of talent in rural areas, remote areas, and poor conditions.

Lack of entrepreneurial awareness. Due to the shackles of the traditional concept of pursuing stability and fear of risk taking, most graduates are more likely to stay at the "finding a job" stage in their employment issues rather than to start their own business [1]. There is a psychological dependence. Most university students are now only children. When faced with tremendous pressure from employment, some classmates are like ostriches. They sleep all day, play games, use negative methods to escape, give their choices to their parents, or hope that the heavens when the pie is 
dropped, the chance suddenly comes to the head.

\subsection{Social Issues}

The existing teaching structure and knowledge system are irrational. There is an increasing demand for comprehensive talents in society. Nowadays, university students tend to focus on only one skill, especially the neglect of liberal arts education. As a result, most of the science graduates can't communicate with others even though they are extremely talented. Expressing its own advantages has seriously affected student employment.

Exam-oriented education leads students to have solid knowledge of books, but lacks hands-on ability and innovative ideas. The curriculum setting of higher education has lagged behind and cannot adjust the professional structure in time, which results in the disconnection between the majors studied by college students and social needs, and aggravates the seriousness of the employment of college students.

\subsection{Employer problem}

The employer employment system is unreasonable. Employers are very demanding when recruiting university graduates. While paying attention to academic qualifications, they also place great emphasis on prestigious university graduates, ignoring the students' potential and their malleability. This has led to some outstanding graduates of ordinary colleges and universities to fail to find an ideal job.

There is gender and source discrimination. Due to various factors such as the physiological factors and reproductive marriage of female college students, some of the female college students face more barriers and difficulties than male college students when they are looking for a job. Some units consider more closely the business conditions of the unit and the closeness of local contacts. It is hoped that the recruited college students will have local accounts and do not have to solve practical problems such as housing, which is not conducive to the fair competition of university graduates.

\section{The main manifestations of college students' employment mental disorders}

\subsection{Anxiety .}

Anxiety is an unpleasant emotion that arises when people subjectively expect that things and situations such as setbacks, threats, and pressure will come and they feel that they have no effective response measures [1].

Among graduates, employment anxiety is a common psychological characteristic. Different students may experience anxiety due to different situations. For example, some students are worried that they may not be able to find stable, high-paying or decent jobs. Some students are afraid of finding professional counterparts; some students find reality. The gap between the ideal and the ideal leads to a greater psychological gap and anxiety; the students who have been unable to find a job see more and more students who find work around them, and they become increasingly annoyed. As time goes by, anxiety will become increasingly serious. In particular, some students living in poverty have more psychological pressure.

\subsection{Depression.}

Depression is characterized by significant and lasting depressive mood. It is mainly manifested in the lack of confidence in failing matters, being listless and uninterested in anything, and unwilling to communicate with others.

In the process of finding a job, college students often experience setbacks and failures. They are not recognized by the job-seeking organization and their self-confidence is undermined. This leads to depression. The bad moods of anxiety, depression, irritability and so on caused by high-intensity employment pressure for job-seeking college students are employment depression. Undergraduate 
graduates who are depressed are overly sensitive to psychology and have slight discomfort in their lives. It is difficult to calm their emotions.

Depression cannot be underestimated in the employment of college students, must be through active and effective psychological counseling to ease the mood and prevent becoming a serious psychological disorder.

\subsection{Inferiority.}

Inferiority is a manifestation of a lack of self-confidence. The main performance is to look down on yourself and evaluate your ability too low. The most common reason for the development of inferiority is that students cannot objectively understand themselves. For example, some students think that they are not beautiful, some students have poor performance, or there are some barriers to communication. If such students are hit in the job search, they will definitely suffer. Have a serious inferiority complex.

A strong sense of inferiority makes college students pessimistically disappointed, frustrated with job search, and lack of self-motivation. This will inevitably become the biggest stumbling block for college students seeking a job.

\subsection{Dependency.}

Reliance psychology refers to college students' lack of independence in their employment and their ability to take responsibility. These students lacked the spirit of progress. In the face of huge employment competition, some students took measures to avoid stress; some students hoped that good job opportunities would suddenly come to their heads, and they would find it satisfactory if they did not need to put much effort into it. The work, but the reality often makes this part of the classmates waste time in reading novels and playing games.

Some students place their hope of finding a job on their parents or relatives and elders. They expect that family members will use various forces to provide them with ready-made and superior job.

\section{Countermeasures}

In order to solve the employment problem of college students, and eliminate the psychological barrier in Employment. There are many reasons that make it difficult for college students to find a job. Solving this problem is a systematic process that requires the joint efforts of employers, college students, universities, and society. The phenomenon of employment of university graduates has become a major concern of the society. The government should establish a standardized and unified graduate employment market and employment protection mechanism, strengthen the supervision of employers, combat discriminatory policies, and ensure the legality of university graduates and employers. Colleges and universities should adjust their professional structure to link them with social needs.

\subsection{Change the concept of employment of college students and establish a correct view of employment.}

The primary task of college students is to study, and the success of their studies is undoubtedly the strong backing of employment. Students should be made aware that their personal abilities must meet the requirements of employers, they must constantly improve themselves, strengthen their professional skills, and enhance their employment competitiveness. In addition to the study of compulsory courses, you should also broaden your knowledge, train your eloquence, and use your computer skillfully, so that you can work toward a goal that is versatile and versatile.

Provide students with various training opportunities, such as interviewing skills training, etc., to enhance the competitiveness of employment. Encourage students to participate in various competitions, develop hands-on practical skills, and overcome fear and fear. Improve self-cultivation, cultivate integrity awareness. 


\subsection{Employment and re-employment first, and strengthen student employment guidance}

The employment guidance for college students should start from the beginning of college admission and conduct career planning education so that students can correctly understand their own advantages and disadvantages, to find their own interests and hobbies, and find directions for future employment. In addition, from the beginning of enrollment, as a counselor, students should be given some appropriate pressure about employment, so that they can improve their employability during the university.

Strengthening the training of teachers in the career guidance courses to systematize their knowledge is not only limited to solving the difficulties that the students are facing for the time being, but is to provide students with a full course of employment guidance. Through the web, Weibo and other new media in time for the students to release the latest recruitment information, to provide students with more employment opportunities, expand employment channels.

\subsection{Weaken the consciousness of elites and encourage college students to start their own businesses and use entrepreneurship to promote employment}

Self-employment of college students is a very good road to success, allowing students to understand a series of preferential policies of the country and all levels of government to ease the employment pressure on college students. The primary difficulties and obstacles faced by college students in starting a business are not lack of experience, lack of funds, and lack of accumulation of personal connections, but lack of courage [2]. Therefore, for students with entrepreneurial ideas, we must help analyze whether it is feasible, do a good job of market research, help them take the first step in all aspects, and use other successful students as examples.

\subsection{Help students to change employment concepts and correctly face the reality}

From the time students enter the school, career planning is required to adjust employment expectations and establish a good attitude. At the same time, the counselor should focus on enhancing students' self-adjustment ability, so that students can learn objective self-analysis when they encounter employment mental confusion, rather than relying on the help of others.

Guide college students to self-adjust. In the job search process, graduates produce anxiety, depression and other psychological emotions, which is normal. Anxiety can make people feel pressure. This kind of pressure may turn into motivation, encourage people to be positive, and it may transform resistance and make people become jealous. This requires the correct guidance of the counselor.

Counselors should communicate with students in peacetime education to analyze their own strengths and weaknesses, analyze the current employment situation, and provide them with objective and practical advice, so that students can objectively understand themselves and improve their own psychological quality. It is also necessary to strengthen anti-frustration training and strengthen the sense of competition so that students can have positive and optimistic attitudes to face employment pressure and stand out in the competitive competition.

Provide employment guidance for graduates. Practice has proved that the employment guidance of college students plays an important role in helping students adjust their mentality, self-adjustment, and successful employment. As far as possible, college students can establish goals in the early stage of job search, make them continue to learn in the process of job search, and strive to improve their own abilities; strengthen the employment skills training for college graduates, and set up special seminars for graduates, such as teacher recruiting, civil service examinations, and interviewing skills. And so on, so that college students have agility to adapt to improve the success rate of job hunting.

If you want to succeed in your job search, you must have the appropriate ability to back it up. Therefore, college students should regard upgrading their abilities as their primary task. Schools should conduct relevant training according to the graduates' professional characteristics and use social practice platforms to improve the college students' organizational management capabilities 
and interpersonal skills. Besides, we should pay attention to the ability to train college students to adapt to society and integrate into society.

\section{Acknowledgement}

[Foundation items]Supported by the Fundamental Research Funds of China West Normal University, "A long-term mechanism of cultivating college students' sense of social responsibility -based on the perspective of socialist core values"(416565)

\section{Reference}

[1] Yang Xinying, Discussing the Problem of Employment Difficulty for University Students[J]. China Light Industry Education, 2009,(1):77-80.

[2] Zhao Gang, The Role of College Counselors in the Self-entrepreneurial Education of University Students [J]. Teaching and Education (University Forum), 2010, (1):92-93

[3] Zhu Jinxu, the Causes and Countermeasures for the Difficulties in the Current Employment of University Students [D].

[4] Tan Lei. Psychological analysis of college student employment pressure and some suggestions [J]. Journal of Changchun Institute of Education. 2010(26):22-24

[5] Wu Xue. Analysis of the causes of psychological barriers in the employment of college students and its countermeasures[J]. Journal of Chifeng College(Natural Science Edition). 2011(6):121-123

[6] Wu Limei. Research on current college students' psychological barriers to employment and the countermeasures [J]. Journal of Jilin Provincial Institute of Education. 2006 (22) :47-48.

[7] Wang Chao. Contemporary college student employment psychological barriers and adjustment[D]. 